\title{
Low Dose of Dipotassium Glycyrrhizate Counteracts Atherosclerosis Progression in Apoe-/- Female Mice
}

\author{
Francesca Palone $^{\mathrm{a}} \quad$ Emanuela Pasquali $^{\mathrm{b}}$ Paola Giardulloc ${ }^{c}$ Laura Stronati $^{\mathrm{d}}$ \\ Roberta Vitali $^{\mathrm{b}}$ Mariateresa Mancuso ${ }^{\mathrm{b}}$ \\ a Pediatric Gastroenterology and Liver Unit, Department of Pediatrics, Sapienza University of Rome, Rome, Italy; \\ ${ }^{b}$ Laboratory of Biomedical Technologies, Italian National Agency for New Technologies, Energy and Sustainable \\ Economic Development, ENEA, Rome, Italy; ' Department of Radiation Physics, Guglielmo Marconi University, Rome, \\ Italy; ${ }^{\mathrm{d}}$ Department of Molecular Medicine, Sapienza University of Rome, Rome, Italy
}

Dear Editor,

Recently, Ding et al. [1] reported that administration of glycyrrhizin $(50 \mathrm{mg} / \mathrm{kg} /$ day), a glycoconjugated triterpene produced by the licorice plant Glycyrrhiza gla$b r a$, reduced high-fat diet-induced atherosclerosis in $A p o e^{-/-}$mice by significantly decreasing serum high-mobility group box protein 1 (HMGB1) and lipid levels and by increasing the Treg/Th17 ratio.

Several natural compounds, such as krill oil, vitamin $\mathrm{D}$, and dipotassium glycyrrhizate (DPG), a salt of glycyrrhizin, have been extensively investigated in our laboratory as therapeutic options for the treatment of intestinal inflammation, showing reliable anti-inflammatory properties [24]. Currently, atherosclerosis is thought as a chronic disease in which systemic inflammation underlies the accumulation of plaques in the arterial intima. Thus, we also considered intriguing possibility to use DPG, a natural compound with known anti-inflammatory properties and scarce or negligible side effects [5], as a good strategy to reduce atherosclerotic lesions.

Francesca Palone and Emanuela Pasquali contributed equally to the paper.
Cardiovascular disease (CVD) remains the most common cause of death in both males and females; however, in the last decades, female CVD deaths exceeded those of males [6-8]. Furthermore, most of the risk factors for CVD (hypertension, high blood cholesterol level, lack of physical activity, and obesity) are similar for males and females, but smoking has a greater negative effect in females [9]. Notably, the influence of gender on atherosclerosis development has also been described in animal models. Indeed, female $A p o E^{-/-}$mice develop significantly increased aortic atherosclerotic lesion and intima/media thickness compared to male mice [10]. Despite these findings, most in vivo studies have been carried out on males. To overcome this gap, here, we used female $A p o E^{-/-}$mice.

For our purposes, 14 week-old $A p o E^{-/-}$ female mice ( $n=8$ /group), fed a standard diet, were treated daily with $8 \mathrm{mg} / \mathrm{kg} /$ day DPG or vehicle by oral gavage for 100 days (approx. 14 weeks). Since effects on blood pressure, mediated by cortisol accumulation [11], have previously been attributed to DPG [12], the cortisol level was monthly analyzed by ELISA (MyBiosource, San Diego, CA, USA) in the total serum. Serum cholesterol, low-density lipoprotein (LDL), and high-density lipoprotein (HDL) concentrations were also evaluated at the same time points by Mouse Cholesterol ELISA Kit (MyBioSource and EMELCA Bioscience, Breda, The Netherlands) and by HDK and LDL/VLDL Quantitation Kit (Sigma-Aldrich), respectively. At the end of treatment, hearts and descending thoracic aortas (DTA) were collected and analyzed as described in our previous work [13]. Specifically, DTA ( $n=8$ /group) were cut longitudinally, pinned en face, and stained with Oil Red O stain. Plaque density (number of plaques $/ \mathrm{mm}^{2}$ ) was quantified on digital images of the aorta (from the aortic arch down to the diaphragm) captured with a Leica digital camera and analyzed by the software NIS-Elements BR4.00.05 (Nikon Instruments S.p.A., Florence, Italy). Heart sections were cut in a plane perpendicular to the aorta axis and, once the aortic root was identified by the appearance of aortic valve leaflets, serial sections were collected and stained with Masson's trichrome or underwent morphometric analyses and immunohistochemistry to assess CD68 and a-SMA expression.

\section{KARGER}

(c) 2019 S. Karger AG, Basel

E-Mail karger@karger.com

www.karger.com/jvr
Dr. Roberta Vitali and Dr. Mariateresa Mancuso

Laboratory of Biomedical Technologies, Italian National Agency for New Technologies Energy and Sustainable Economic Development, ENEA Via Anguillarese 301, IT-00123 Rome (Italy)

E-Mail: roberta.vitali@enea.it, or mariateresa.mancuso@enea.it 

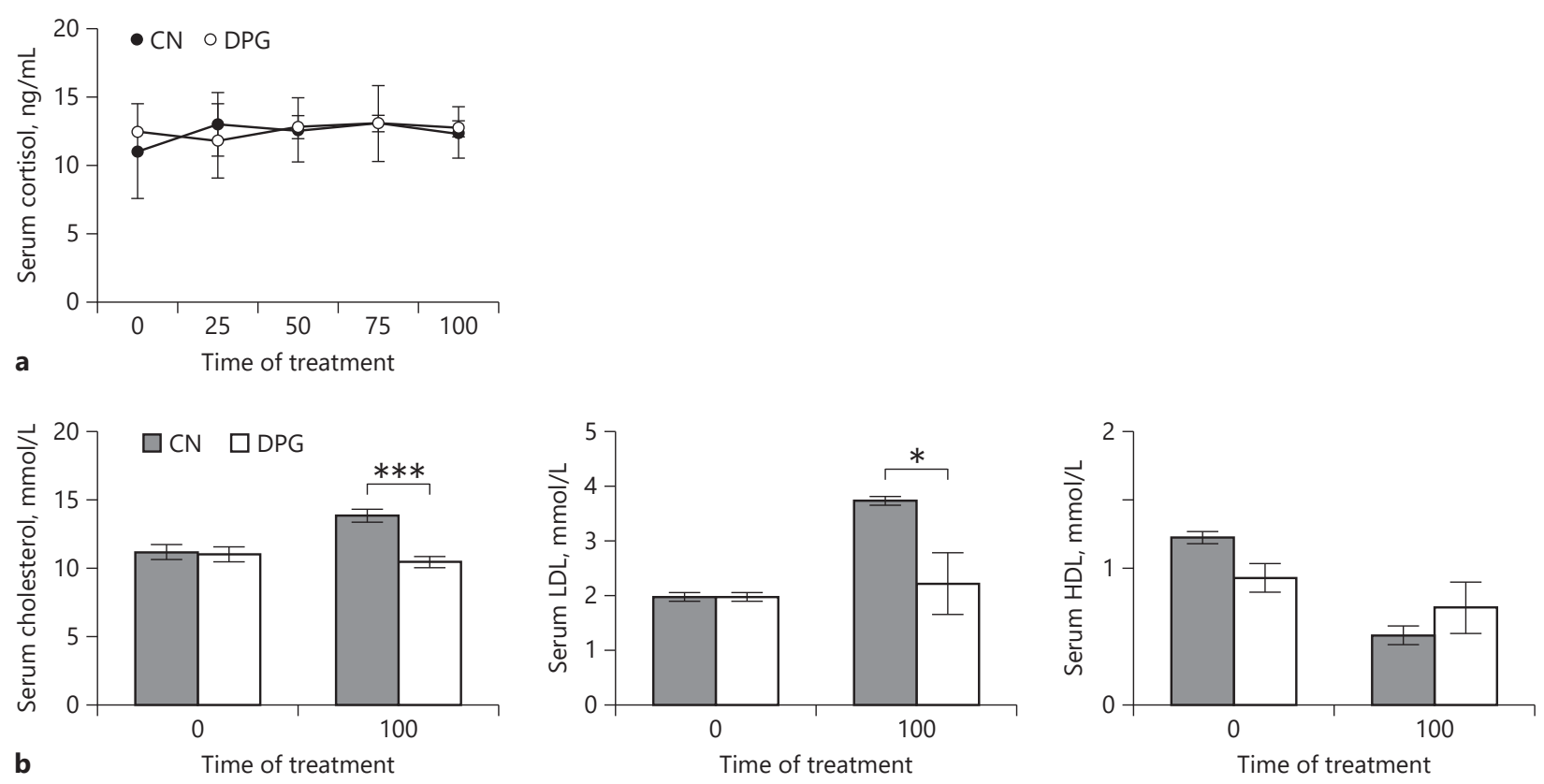

Fig. 1. Effect of DPG on serum cortisol and cholesterol levels in female $A p o E^{-/-}$mice and age-matched controls (CN) 14 weeks after treatment. Serum cortisol (a), cholesterol, LDL, and HDL concentrations (b) were analyzed by ELISA. Data are reported as mean \pm SEM. Differences were tested with Student's $t$ test. ${ }^{* * *} p<$ $0.001,{ }^{*} p<0.05$. The concentration of cortisol is given as $\mathrm{ng} / \mathrm{mL}$.

For cholesterol determination, murine sera were diluted (1:5), and the concentration is given as $\mathrm{mmol} / \mathrm{L}$. For cortisol and cholesterol, ELISA changes in the optical density were measured at $450 \mathrm{~nm}$; for $\mathrm{LDL}$ and $\mathrm{HDL}$, the concentration is given as $\mathrm{mmol} / \mathrm{L}$, and changes in the optical density were measured at $560 \mathrm{~nm}$. Each sample (8 samples per group) was analyzed in duplicate.

Macroscopically, we did not observe any heart changes (i.e., cardiac hypertrophy) in DPG-treated $A p o E^{-/-}$mice compared with controls. In support of our results, other authors reported that in $A p o E^{-/-}$mice, heart changes were related to and/or aggravated by aging and Western diet [14]. Our results showed that the cortisol level is not modulated by DPG treatment (serum cortisol: matched controls [CN]: $12.37 \mathrm{ng} / \mathrm{mL} \pm 1.86$; DPG 12.70 $\mathrm{ng} / \mathrm{mL} \pm 0.59, p=0.25$; Fig. 1a), suggesting that at this concentration, DPG does not raise blood pressure, an important side effect of licorice consumption. Furthermore, DPG-treated mice showed significantly reduced levels of serum cholesterol and LDL compared with the age-matched control group (serum cholesterol: $\mathrm{CN}$ : 13.96 $\mathrm{mmol} / \mathrm{L} \pm 0.45 ; \mathrm{DPG} 10.50 \mathrm{mmol} / \mathrm{L} \pm 0.42$, $p<0.001$; serum LDL: CN: $3.76 \mathrm{mmol} / \mathrm{L} \pm$ 0,06; DPG $2.24 \mathrm{mmol} / \mathrm{L} \pm 0.56, p<0.05$; Fig. 1b). No change in HDL concentration was observed after DPG treatment (Fig. 1b).
The density of the atherosclerotic lesion (number of plaques $/ \mathrm{mm}^{2}$ ) in the DTA region was not significantly affected by DPG treatment in our experimental conditions (Fig. 2a, b). Conversely, cross-sectional analysis of the aortic root clearly demonstrated that DPG treatment induced a decrease in the plaque area, approaching borderline statistical significance (Fig. 2c-e). Together with the decreased size, DPGtreated mice showed plaques with a statistically significant lower necrotic core, one of the defining characteristics of a vulnerable plaque, compared with control mice (Fig. 2f). The more vulnerable status of plaques in untreated mice is consistent with the higher percentage of foam cells (CD68+; Fig. 2g) and smooth muscle cells (a-SMA+; Fig. 2i) migrating into the plaque from the underlying media compared with plaques from DPG-treated mice (Fig. 2h, j).

HMGB1, a known inflammatory mediator, is overexpressed in atherosclerotic lesions and exerts proatherogenic effects by stimulating macrophage migration, induc-
Fig. 2. Effects of DPG on atherosclerosis. Representative en face preparations of DTA and aortic root sections from female ApoE ${ }^{-/-}$mice 14 weeks after treatment with $8 \mathrm{mg} / \mathrm{kg} /$ day DPG or from agematched controls. Plaque density in the DTA: representative images (a) and histogram (b) of all samples analyzed $(n=8$ / group). Aortic root sections (Masson's trichrome stain) from CN (c) and DPG-treated mice (d). Graphic representation of the plaque area (e) and necrotic core (f) measured on aortic root cross-sections of all samples analyzed ( $n=8$ /group). Sections of atherosclerotic plaques immunostained with antibodies against CD68 $(\mathbf{g}, \mathbf{h})$ and a-SMA (i, $\mathbf{j})$ from CN- and DPG-treated mice. Data are shown as mean \pm SEM. Differences were tested with Student's $t$ test. $* p=0.0168$.

(For figure see next page.)

Palone/Pasquali/Giardullo/Stronati/ Vitali/Mancuso 


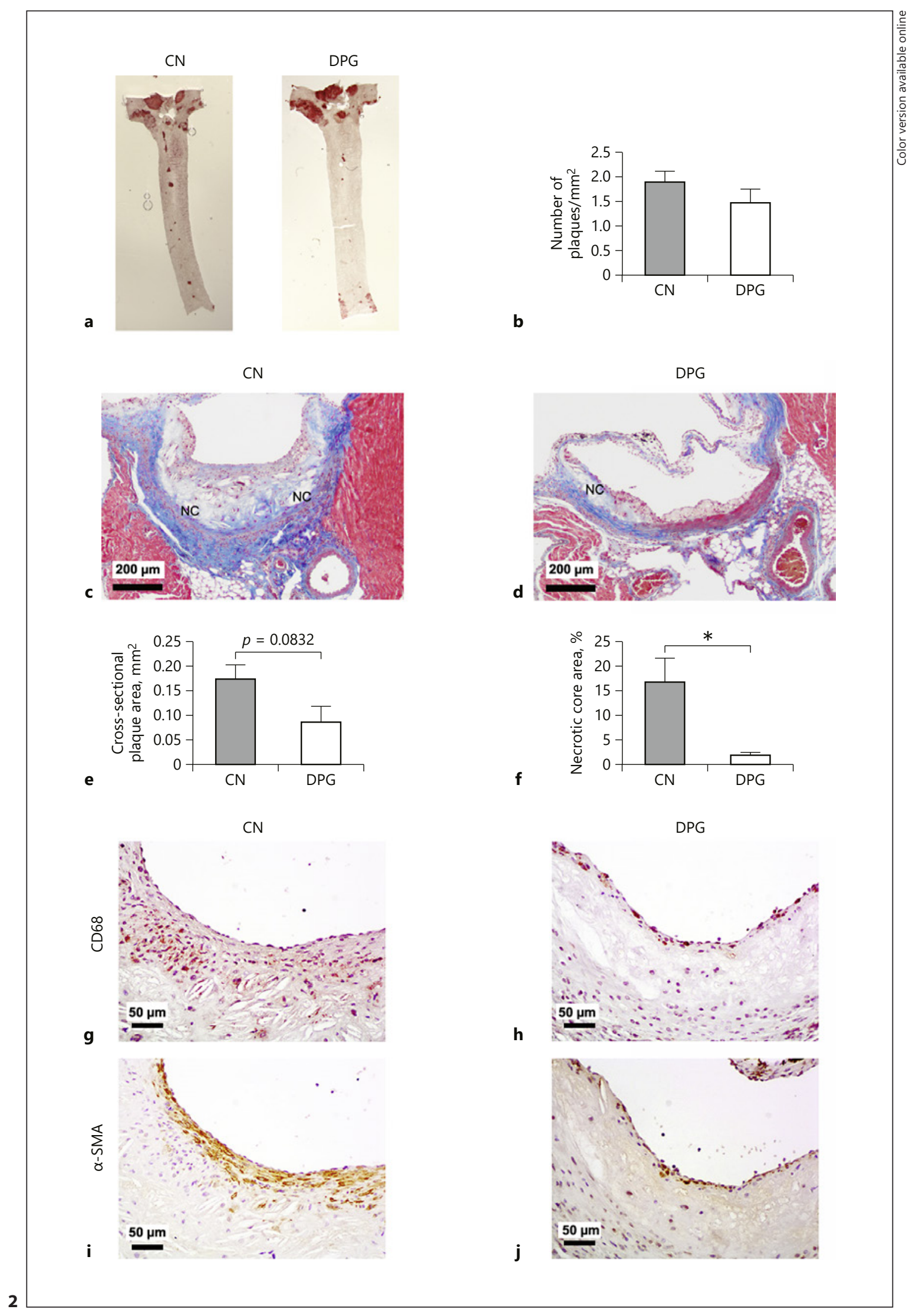


ing proinflammatory cytokines and promoting the accumulation of immune and smooth muscle cells [15]. Thus, the selectively targeting of HMGB1 by DPG, a small inhibitor of HMGB1 [16], could decrease HMGB1-mediated local inflammation, inducing improvement in atherosclerotic plaque progression.

Although our data are in agreement with those reported by Ding et al. [1] regarding the beneficial effect of licorice on the atherosclerosis progression, important additional information can be extrapolated from our study. Indeed, in agreement with the current evidence of a progressive increase in atherosclerosis incidence among female, our study was carried out in female mice, during standard diet and using a 5 -fold lower concentration of DPG compared to the study by Ding et al. [1].

In conclusion, our study highlights that a low dosage of DPG counteracts atherosclerosis progression occurring during standard diet. This finding opens the possibility to propose DPG administration in combination with balanced diet to predisposed individuals without the concern about the rise in blood pressure, an important parameter to be considered with higher doses.

\section{References}

1 Ding JW, Luo CY, Wang XA, Zhou T, Zheng XX, Zhang ZQ, et al. Glycyrrhizin, a HighMobility Group Box 1 Inhibitor, Improves Lipid Metabolism and Suppresses Vascular Inflammation in Apolipoprotein E Knockout Mice. J Vasc Res. 2018;55(6):365-77.

2 Vitali R, Palone F, Cucchiara S, Negroni A, Cavone L, Costanzo M, et al. Dipotassium Glycyrrhizate Inhibits HMGB1-Dependent Inflammation and Ameliorates Colitis in Mice. PLoS One. 2013 Jun;8(6):e66527.

3 Vitali R, Palone F, Pierdomenico M, Negroni A, Cucchiara S, Aloi M, et al. Dipotassium glycyrrhizate via HMGB1 or AMPK signaling suppresses oxidative stress during intestinal inflammation. Biochem Pharmacol. 2015 Oct;97(3):292-9.

4 Costanzo M, Cesi V, Palone F, Pierdomenico M, Colantoni E, Leter B, et al. Krill oil, vitamin $\mathrm{D}$ and Lactobacillus reuteri cooperate to reduce gut inflammation. Benef Microbes. 2018 Apr;9(3):389-99.

5 Li JY, Cao HY, Liu P, Cheng GH, Sun MY. Glycyrrhizic acid in the treatment of liver diseases: literature review. BioMed Res Int. 2014; 2014:872139. can women. Nutr Metab Cardiovasc Dis. 2010 Jul;20(6):386-93.

7 Sciomer S, Moscucci F, Dessalvi CC, Deidda $\mathrm{M}$, Mercuro G. Gender differences in cardiology: is it time for new guidelines? J Cardiovasc Med (Hagerstown). 2018 Dec;19(12):685-8.

8 Go AS, Mozaffarian D, Roger VL, Benjamin EJ, Berry JD, Borden WB, et al.; American Heart Association Statistics Committee and Stroke Statistics Subcommittee. Heart disease and stroke statistics-2013 update: a report from the American Heart Association. Circulation. 2013 Jan;127(1):e6-245.

9 Yahagi K, Davis HR, Arbustini E, Virmani R. Sex differences in coronary artery disease: pathological observations. Atherosclerosis. 2015 Mar;239(1):260-7.

10 Smith DD, Tan X, Tawfik O, Milne G, Stechschulte DJ, Dileepan KN. Increased aortic atherosclerotic plaque development in female apolipoprotein E-null mice is associated with elevated thromboxane A2 and decreased prostacyclin production. J Physiol Pharmacol. 2010 Jun;61(3):309-16.

11 Kelly JJ, Mangos G, Williamson PM, Whitworth JA. Cortisol and hypertension. Clin Exp Pharmacol Physiol Suppl. 1998 Nov;25 S1:S51-6.
6 Zhang Y. Cardiovascular diseases in Ameri-

\section{Acknowledgement}

The authors thank the DMG Italia Srl for providing DPG.

\section{Disclosure Statement}

The authors have no conflicts of interest to declare.

\section{Funding Sources}

Intramural institutional funding was received.
12 Zhang MZ, Xu J, Yao B, Yin H, Cai Q, Shrubsole MJ, et al. Inhibition of 11beta-hydroxysteroid dehydrogenase type II selectively blocks the tumor COX-2 pathway and suppresses colon carcinogenesis in mice and humans. J Clin Invest. 2009 Apr;119(4):876-85.

13 Mancuso M, Pasquali E, Braga-Tanaka I 3rd, Tanaka S, Pannicelli A, Giardullo P, et al. Acceleration of atherogenesis in ApoE-/- mice exposed to acute or low-dose-rate ionizing radiation. Oncotarget. 2015 Oct;6(31):3126371.

14 Vasquez EC, Peotta VA, Gava AL, Pereira TM, Meyrelles SS. Cardiac and vascular phenotypes in the apolipoprotein E-deficient mouse. J Biomed Sci. 2012 Feb;19(1):22.

15 Kanellakis P, Agrotis A, Kyaw TS, Koulis C, Ahrens I, Mori S, et al. High-mobility group box protein 1 neutralization reduces development of diet-induced atherosclerosis in apolipoprotein e-deficient mice. Arterioscler Thromb Vasc Biol. 2011 Feb;31(2):313-9.

16 Mollica L, De Marchis F, Spitaleri A, Dallacosta C, Pennacchini D, Zamai M, et al. Glycyrrhizin binds to high-mobility group box 1 protein and inhibits its cytokine activities. Chem Biol. 2007 Apr;14(4):431-41. 